Probing the surface structure of divalent transition metals using surface specific solid-state NMR spectroscopy

H. E. Mason, S. J. Harley, R. S. Maxwell, S. A. Carroll

December 13, 2011

Environmental Science and Technology 
This document was prepared as an account of work sponsored by an agency of the United States government. Neither the United States government nor Lawrence Livermore National Security, LLC, nor any of their employees makes any warranty, expressed or implied, or assumes any legal liability or responsibility for the accuracy, completeness, or usefulness of any information, apparatus, product, or process disclosed, or represents that its use would not infringe privately owned rights. Reference herein to any specific commercial product, process, or service by trade name, trademark, manufacturer, or otherwise does not necessarily constitute or imply its endorsement, recommendation, or favoring by the United States government or Lawrence Livermore National Security, LLC. The views and opinions of authors expressed herein do not necessarily state or reflect those of the United States government or Lawrence Livermore National Security, LLC, and shall not be used for advertising or product endorsement purposes. 


\section{Probing the surface structure of divalent transition metals using surface specific solid-state NMR spectroscopy}

\begin{tabular}{|r|l|}
\hline Journal: & Environmental Science \& Technology \\
\hline Manuscript ID: & Draft \\
\hline Manuscript Type: & Article \\
\hline Author: & $\mathrm{n}$.a \\
\hline Complete List of Authors: & $\begin{array}{l}\text { Mason, Harris E.; Lawrence Livermore National Laboratory, Physical } \\
\text { and Life Sciences Department } \\
\text { Harley, Stephen; Lawrence Livermore National Laboratory, Physical } \\
\text { and Life Sciences Directorate } \\
\text { Maxwell, Robert; Lawrence Livermore National Laboratory, Physical } \\
\text { and Life Sciences Directorate } \\
\text { Carroll, Susan; Lawrence Livermore National Laboratory, Physical and } \\
\text { Life Sciences Department }\end{array}$ \\
\hline
\end{tabular}

\section{SCHOLARONE Manuscripts}




\section{Probing the surface structure of divalent transition}

2

3

4

5

6

7 AUTHOR EMAIL: mason42@1lnl.gov

\section{RECEIVED DATE} ABSTRACT

\section{metals using surface specific solid-state NMR}

\section{spectroscopy}

Harris E. Mason ${ }^{1 *}$, Stephen J. Harley ${ }^{1}$, Robert S. Maxwell ${ }^{1}$, and Susan A. Carroll ${ }^{1}$

AUTHOR ADDRESS: ${ }^{1}$ Physical and Life Sciences Directorate, Lawrence Livermore National Laboratory, 7000 East Ave. Livermore, CA 94551

TITLE RUNNING HEAD: NMR spectroscopic investigation of divalent metal sorption

Environmental and geochemical systems containing paramagnetic species could benefit by using nuclear magnetic resonance (NMR) spectroscopy due to the sensitivity of the spectral response to small amounts paramagnetic interactions. In this study, we apply commonly used

4 solid-state NMR spectroscopic methods combined with chemometrics analysis to probe sorption

5 behavior of the paramagnetic cations $\mathrm{Cu}^{2+}$ and $\mathrm{Ni}^{2+}$ at the amorphous silica surface. We exploit

the unique properties of paramagnets to derive meaningful structural information in these

7 systems at low, environmentally relevant cation surface loadings by comparing the NMR

response of sorption samples to paramagnetic free samples. These data suggest that simple

sorption models where the cation sorbs as inner sphere complexes at negatively charged, 
20 deprotonated silanol sites is appropriate. These results help constrain sorption models that are

21 used to describe metal fate and transport.

22 KEYWORDS: Solid-state NMR spectroscopy, paramagnets, sorption

23 INTRODUCTION

24 Models which can accurately predict the fate and transport of subsurface contaminants

25 are an area of intense geochemical research. Extensive work has gone into developing models

26 which can accurately predict the behavior of sorbed cations based solely on measured solution

27 chemistry.[1-6] These models are based on electrostatic interactions between solution species

28 and mineral surfaces, and have demonstrated some success in modeling the sorption behavior

29 over a range of solution chemistries. However, these models are often over defined, and

30 therefore need accurate spectroscopic studies to constrain input parameters.

31 Detailed structural information about the sorbed cation complexes has been gleaned from

32 various spectroscopic investigations of reactions between divalent metals and minerals surfaces.

33 Specifically, we focus on the previous work aimed at the interactions of paramagnetic cations

$34 \mathrm{Cu}^{2+}$ and $\mathrm{Ni}^{2+}$ with silicate mineral surfaces. A wealth of information about the sorption of $\mathrm{Cu}$ on

35 the amorphous silica surface has been derived from X-ray adsorption (XAS) and electron

36 paramagnetic resonance (EPR) spectroscopic studies.[7-12] These studies find that the $\mathrm{Cu}$ binds

37 strongly to the silica surface as inner sphere complexes, and that $\mathrm{Cu}$ diamers can form at low

38 surface coverages.[9, 10] Contrasting EPR results have also suggested that surface sorption is

39 limited and that $\mathrm{Cu}(\mathrm{OH})_{2}$ precipitation dominates.[7, 8] Similarly, XAS methods have also been

40 applied to the study of Ni interactions with mineral surfaces.[13-16] These studies have

41 suggested that at short reaction times the Ni forms inner sphere complexes, but that at longer

42 times the reactions are dominated by the formation of Ni surface precipitates [13]. 
43 The study of $\mathrm{Cu}$ and Ni containing systems by NMR spectroscopy presents some unique 44 challenges and opportunities to derive structural information from simple NMR experiments. In 45 the fields of environmental chemistry and geochemistry the study of systems containing

46 paramagnetic species with NMR spectroscopy has largely been avoided due to the perception 47 that their presence precludes the observation of useful structural information. Therefore, most

48 NMR based sorption studies have focused on loading surfaces with moderately high

49 concentrations of diamagnetic species such as $\mathrm{Na}^{+}, \mathrm{Cs}^{+}, \mathrm{Al}^{3+}$ and $\mathrm{PO}_{4}{ }^{3-}$ which are easily

50 observed with standard solid state NMR methods.[17-21] However, strong interactions between

51 NMR observable nuclei and the unpaired electrons present in paramagnetic species have been

52 successfully exploited to derive precise structural information on organo-metallic complexes [22, 53 23].

54 In this study, we exploit what are traditionally considered the detrimental effects of 55 paramagnetic species on the NMR spectral response to derive information about the surface 56 structure of sorbed metal species at low, environmentally pertinent surface loadings. We present

57 the results of NMR spectroscopic investigation of $\mathrm{Cu}^{2+}$ and $\mathrm{Ni}^{2+}$ sorption on the amorphous silica 58 surface. The methods employed here allow us to identify the surface ligand with which these 59 cations interact. It is largely assumed based on electrostatic arguments that these cations should 60 prefer to bind at negatively charged surface sites (i.e. $>\mathrm{SiO}^{-}$), no study has directly investigated 61 this assertion.

\section{MATERIALS AND METHODS}

\section{Sorption Experiments}

64 The $\mathrm{Cu}^{2+}$ and $\mathrm{Ni}^{2+}$ sorption experiments were conducted as a function of surface loading 65 at pH 8 and 9, respectively. pH conditions were maintained through the periodic addition of 0.01 
$66 \mathrm{~N} \mathrm{NaOH}$ by a Metrohm Titrando 902 autotitration unit. To ensure surface equilibration, $0.5 \mathrm{~g}$ of

67 high surface area amorphous silica (Mallinkrodt silica: $306 \mathrm{~m}^{2} / \mathrm{g}$ surface by BET, $75-100 \mu \mathrm{m}$

68 particle size) was reacted in $100 \mathrm{ml}$ of $0.1 \mathrm{M} \mathrm{NaCl}$ solution at the desired $\mathrm{pH}$ for $22 \mathrm{hrs}$ before

69 proceeding with the sorption reaction. After the equilibration step, an aliquot of the cation stock

70 solution $\left(10 \mathrm{mM} \mathrm{CuCl}_{2}\right.$ or $\left.1 \mathrm{mM} \mathrm{NiCl}_{2}\right)$ was added in order to achieve the desired initial

71 concentration (Table 1) and the system was allowed to react for 2 hrs. For NMR analyses, the

72 samples were collected by suction filtration, and dried overnight at $60{ }^{\circ} \mathrm{C} .{ }^{1} \mathrm{H}$ NMR data (vida

73 infra) showed that a hydration layer remained on the silica surface following the drying

74 procedure indicating that it did not significantly alter the surface structure. Final surface loadings

75 were determined from solution chemistry by collecting $10 \mathrm{~mL}$ aliquots of the reaction solution

76 immediately after the $22 \mathrm{hr}$ equilibration period and after the $2 \mathrm{hr}$ sorption reaction. These

77 solutions were filtered through a $0.2 \mu \mathrm{m}$ syringe filter and submitted to ICPMS analysis. Control

78 samples for baseline comparison of the NMR response were produced at $\mathrm{pH} 8$ and 9 by

79 immediately halting the reaction after the equilibration step. A sample of the $\mathrm{pH} 9$ control sample

80 was also physically mixed with $\mathrm{Ni}(\mathrm{OH})_{2}$ colloids in an agate mortar and pestle in order to test the

81 response to the presence of a seperate precipitated phase.

82 NMR Spectroscopy:

83 Solid-state ${ }^{29} \mathrm{Si}$ single pulse $(\mathrm{SP})$ and ${ }^{29} \mathrm{Si}\left\{{ }^{1} \mathrm{H}\right\}$ cross polarization magic angle spinning

84 (CP/MAS) experiments were conducted on a $300 \mathrm{MHz}$ Tecmag Apollo spectrometer at operating

85 frequencies of 59.63 and $300.19 \mathrm{MHz}$ for ${ }^{29} \mathrm{Si}$ and ${ }^{1} \mathrm{H}$, respectively. The ${ }^{29} \mathrm{Si}\left\{{ }^{1} \mathrm{H}\right\} \mathrm{CP} / \mathrm{MAS}$

86 spectra were collected over a range of $\mathrm{CP}$ contact times at spinning rate of $3 \mathrm{kHz}$ using a

87 Chemagnetics probe configured for $7.5 \mathrm{~mm}$ (o.d.) rotors. A $6 \mu \mathrm{s}{ }^{1} \mathrm{H}$ excitation pulse was used

88 and ${ }^{29} \mathrm{Si}$ was matched on the +1 sideband of kaolinite. All ${ }^{29} \mathrm{Si}$ spectra were referenced with 
89 respect to tetramethylsilane (TMS) using an external kaolinite standard $\left(\delta_{\mathrm{Si}}=-92 \mathrm{ppm}\right) .{ }^{1} \mathrm{H}$ single

90 pulse (SP) MAS NMR spectra were collected on a $400 \mathrm{MHz}$ Bruker Avance spectrometer at an

91 operating frequency of $400.06 \mathrm{MHz}$. The samples were contained in $4 \mathrm{~mm}$ (o.d) rotor and spun

92 at a $12 \mathrm{KHz}$ spinning rate with a $4 \mathrm{~mm}$ Bruker triple resonance probe. Standard inversion

93 recovery techniques were employed to measure ${ }^{1} \mathrm{H}$ spin-lattice relaxation constants $\left(\mathrm{T}_{1}\right)$. All ${ }^{1} \mathrm{H}$

94 spectra were collected with a $6 \mu$ s excitation pulse and are referenced with respect to an external

95 sample of TMS $\left(\delta_{\mathrm{H}}=0 \mathrm{ppm}\right)$. In order to quantify the NMR spectral intensities for all NMR

96 experiments, the samples were loaded in pre-weighed $\mathrm{ZrO}_{2}$ ceramic rotors, and their weights

97 recorded.

98 Chemometrics analysisof NMR data

99 Chemometric methodologies are a powerful group of techniques that extract relevant 100 spectral information from subtle variations in large multidimensional data sets.[24-26] Here two 101 subsets of chemometrics are utilized: evolving factor analysis (EFA) and multivariate curve 102 resolution (MCR). First EFA[27] is applied to the compiled CP NMR dataset whose rows are 103 comprised of a single $\mathrm{CP}$ spectrum for a characteristic contact time and the columns represent 104 the intensity change for a discrete frequency as a function of contact time. The advantage of 105 EFA is that it merely seeks to compile those components who share similar variant behavior into 106 separate factors and is independent of a chemical model. Those factors that show more variance 107 than the variance of the original spectra contain the dynamics of interest. All other factors were 108 discarded. Then these kept factors are fed into a multivariate curve resolution method utilizing an 109 alternating least squares algorithm (MCR-ALS) to iteratively deconvolute the spectroscopic data 110 matrix (D) into a pure component $(\mathrm{C})$ and pure spectra $\left(\mathrm{S}^{\mathrm{T}}\right)$ profile according to:

$$
\mathrm{D}=\mathrm{CS}^{\mathrm{T}}+\mathrm{E}
$$


$112 \mathbf{E}$ is the residual matrix and contains the variance unexplained by $\mathbf{C S}^{\mathrm{T}}$, here it is assumed to be

113 independent and have constant variance. The subtleties of this technique are explained

114 thoroughly in the literature [28, 29]. This so called soft-model (or model-free) approach is

115 advantageous when a hard-model is unavailable or inadequately describes the spectral response.

116 RESULTS AND DISCUSSION

\section{Identification of ligand adsorption sites}

118 At face value, the individual ${ }^{29} \mathrm{Si}\left\{{ }^{1} \mathrm{H}\right\} \mathrm{CP} / \mathrm{MAS}$ spectra of the sorption samples do not 119 appear much different from the control samples (Figure 1). They all have the same three major 120 peaks present at $-93.4,-103.1$, and $-113.2 \mathrm{ppm}$ which are typically assigned to the $\mathrm{Q}^{2}, \mathrm{Q}^{3}$, and $\mathrm{Q}^{4}$ 121 silica sites. The $\mathrm{Q}^{\mathrm{n}}$ notation refers to the number of bridging oxygens shared with surrounding 122 silica tetrahedra with the $\mathrm{Q}^{2}$ and $\mathrm{Q}^{3}$ site sites representing silanol sites whose remaining oxygens 123 are terminated with silanol protons, and the $\mathrm{Q}^{4}$ site representing fully coordinated internal 124 siloxane groups.[17, 30] Although presence of paramagnetic cations does not change observed 125 peak chemical shifts or widths in the sorption samples, there are large decreases in the integrated 126 spectral intensities of these peaks (Figure 1). Given that individual CP/MAS spectra cannot be 127 treated quantitatively[31], we must consider how the intensity of these peaks vary as a function 128 of the CP contact time to quantify the effects the paramagnetic species have in these systems. 129 We have applied chemometrics analysis to the variable contact time ${ }^{29} \mathrm{Si}\left\{{ }^{1} \mathrm{H}\right\} \mathrm{CP} / \mathrm{MAS}$ 130 spectra, and have identified two unique spectral components whose presence we attribute to the 131 existence of protonated (Figure 2A, blue) and deprotonated (Figure 2A, red) silica surface sites. 132 We see that the two spectral components contain contributions from all three silica sites, but 133 have very different intensity profiles (Figure 2B). The lesser of the two components has an 134 intensity profile which grows in rapidly with an average $\mathrm{T}_{\mathrm{SiH}}$ of $1.0 \mathrm{~ms}$, and decays away with an 
135 average $T_{1 \rho, H}$ of $3 \mathrm{~ms}$. This behavior is characteristic of silica sites which are directly bound to 136 protons [30, 31], and we assign this component to protonated surface silanols $(>\mathrm{SiOH})$. The

137 other site, however, exhibits the opposite behavior with its intensity growing in more slowly and 138 with no observed $\mathrm{T}_{1 \rho, \mathrm{H}}$ decay. If the intensity of this second site is instead plotted as a function 139 of the square root of the contact time then there is a clear linear region in the middle of the 140 profile (Figure 2). This observed behavior is characteristic of a diffusion limited process [32].

141 Therefore, we assign this component to deprotonated silica species, because they are spatially

142 distinct from protons and are observed in the CP/MAS spectra only by long range couplings

143 through spin diffusion. This is further corroborated by the large presence of the $\mathrm{Q}^{4}$ siloxane

144 groups in this component which are by definition deprotonated and are present due to long range

145 couplings (Figure 2A, red). The $\mathrm{Q}^{2}$ and $\mathrm{Q}^{3}$ sites contained in this fraction we assign to

146 deprotonated surface silanol groups $\left(>\mathrm{SiO}^{-}\right)$. We attribute the contribution of the $\mathrm{Q}^{4}$ sites to

147 direct coordination or close proximity $(<5 \AA)$ to the protonated surface silanol groups. Since

148 these $\mathrm{Q}^{4}$ are contained within the bulk silica and unlikely to be important in the sorption process,

149 they will not be discussed further. All other discussion will center on the $\mathrm{Q}^{2}$ and $\mathrm{Q}^{3}$ silanol 150 surface sites.

151 With the assignment of these components to $>\mathrm{SiOH}$ and $>\mathrm{SiO}^{-}$surface groups we can 152 begin to draw conclusions about the sorption of $\mathrm{Cu}^{2+}$ and $\mathrm{Ni}^{2+}$ to the silica surface. We find that 153 changes in the integrated $\mathrm{CP}$ signal intensity can be attributed to the sorption of $\mathrm{Ni}$ and $\mathrm{Cu}$ 154 metals occurs as inner sphere complexes at $>\mathrm{SiO}^{-}$surface sites (Figures 3 and 4 ). When we 155 compare the weight normalized spectral components of the sorption samples to those of the 156 control samples, we observe only slight changes in signal intensity for the protonated fraction, 157 but major changes in the deprotonated fraction. Assuming a conservative surface silanol density 
158 of $2 \mu \mathrm{mol} / \mathrm{m}^{2}$ for amorphous silica at $\mathrm{pH} 8 / 9,[17]$ and the amount of $\mathrm{Cu}$ and $\mathrm{Ni}$ uptake, then 159 surface coverage ranges from about 0.1 to $3 \%$ (Table 1). For both the $\mathrm{Cu}$ and Ni samples, we 160 observe large systematic decreases in the signal intensity of the $>\mathrm{SiO}^{-}$component as a function 161 of surface loading. For the $\mathrm{Cu}$ samples, the intensity of the $\mathrm{Q}^{3}$ peaks relative to those of the 162 control reduces by $37.6 \%$ for the lowest concentration sample $(0.33 \%$ surface coverage $)$ and $16356.6 \%$ for the highest concentration (3.23\% surface coverage). For the Ni samples, these same 164 peaks reduce by $62.5 \%$ for the low concentration sample (0.08\% surface coverage), and $70.9 \%$ 165 for the high concentration sample (2.7\% coverage). If the intensity losses were the result of site 166 blockage alone we should expect these to be proportional to the surface coverage. However, we 167 note the largest decreases in the Ni system where the coverage is lowest. We attribute the larger 168 decreases to the more paramagnetic character of the $\mathrm{Ni}^{2+}$ cation which as two unpaired electrons 169 compared to the single unpaired electron in the $\mathrm{Cu}^{2+}$ cation. The observed effects appear to result 170 only through the interactions with the silica surface with paramagnetic species.

171 We clearly observe a systematic effect in the CP/MAS data as we increase the

172 concentration of paramagnetic species, but we need to test if these effects result only from 173 through bond interactions with the surface, or if they would also occur if a distinct precipitated 174 phase is present. When we analyze the data collected for the $\mathrm{pH} 9$ control sample and the 175 physical mixture of $\mathrm{Ni}(\mathrm{OH})_{2}$ colloids (not shown) we observe no differences between the 176 observed intensities and that of the pristine $\mathrm{pH} 9$ control sample. The absence of an effect in this 177 sample supports our interpretation that intensity changes result from bonding interactions 178 between the sorbed metal species and the $>\mathrm{SiO}^{-}$groups on the amorphous silica surface. 179 Therefore, we propose that in the absence of sorbed paramagnets, ${ }^{1} \mathrm{H}$ magnetization diffusion is 180 efficient between the $>\mathrm{SiOH}$ and $>\mathrm{SiO}^{-}$groups (Figure 5A). In the presence of the sorbed 
181 paramagnetic species this diffusion is inhibited due to the unpaired electron density interacting

182 strongly with the $>\mathrm{SiO}^{-}$(Figure $5 \mathrm{~B}$ ) causing the characteristic decrease in signal intensity we

183 observe with increasing sorbent concentration. These data also suggest that the transition

184 between sorption and precipitation could be identified with NMR spectroscopy with increased 185 surface loadings.

186 All the above structural observations are only possible because of spectral interferences 187 from paramagnetic species. Similar to the above $\mathrm{Ni}(\mathrm{OH})_{2}$ colloid experiment, the absence or 188 decrease in the EPR spectral response in $\mathrm{Cu}$ uptake experiments has been used as evidence for 189 either the precipitation of $\mathrm{Cu}(\mathrm{OH})_{2}$ or the formation of diameric $\mathrm{Cu}$-hydroxide species $[7,8,12]$

190 The understanding is that these phase loses the paramagnetic character of the $\mathrm{Cu}^{2+}$ and will not 191 cause a response in the EPR experiment. Therefore, the presence of such a phase in our samples 192 would be equally ineffective at producing the NMR responses we observe. The large spectral 193 response observed for our highest $\mathrm{Cu}$ loadings suggests that none of the previously suggested

$194 \mathrm{Cu}$-hydroxide phases have formed in our experiments.

195 Identification of external versus internal sorption sites

196 Powerful information about the bonding environment of these cations can also be gleaned 197 by directly observing ${ }^{1} \mathrm{H}$ in a ${ }^{1} \mathrm{H}$ SP/MAS NMR experiment (Figure 6). These results indicate 198 that the surface sorbed metal species strongly interact with surface water species, but interact less 199 strongly with $>\mathrm{SiOH}$. This is evidenced by again comparing the NMR signal obtained for control 200 samples to that of the samples containing surface sorbed metals. What is immediately apparent is 201 the suppression of the $4.7 \mathrm{ppm}$ peak corresponding to water sorbed to the dried silica surface 202 from the spectra of the sorption samples (Figure 6). Also observed is the conspicuous emergence 203 of a strong, sharp (0.1 ppm FWHM) ${ }^{1} \mathrm{H}$ peak near 2 ppm from isolated, weakly H-bonded SiOH 
204 groups $\left(>\mathrm{SiOH}_{\mathrm{w}}\right)$ [30]. Since the silica we used is mesoporous with a significant amount of 205 internal porosity[33], we interpret these $>\mathrm{SiOH}_{\mathrm{w}}$ sites as silanols contained within internal pore 206 spaces. This peak is present in spectra of the control samples, but significantly muted compared 207 to the strong signal from surface water species. In the spectra collected for the Ni samples, the 208 mobile water peak is entirely suppressed, unmasking the sharp peak from $>\mathrm{SiOH}_{\mathrm{w}}$ and a peak 209 peak at $5.5 \mathrm{ppm}$ from strongly $\mathrm{H}$-bonded $>\mathrm{SiOH}$ groups $\left(>\mathrm{SiOH}_{\mathrm{s}}\right)$.[30] This peak is also present 210 as a shoulder in all other ${ }^{1} \mathrm{H}$ spectra, but difficult to resolve from the main $\mathrm{H}_{2} \mathrm{O}$ peak. These $211>\mathrm{SiOH}_{\mathrm{s}}$ sites represent silanols on the external surface which are hydrogen bonded to the surface 212 water species. The strong suppression of the water peaks indicates that these surface waters are 213 strongly interacting with the paramagnetic cation species, and the $>\mathrm{SiOH}$ surface groups are 214 largely unperturbed. The proton NMR provide complementary evidence that $\mathrm{Ni}$ and $\mathrm{Cu}$ sorb to 215 the $>\mathrm{SiO}^{-}$sites near surface water.

216 The measured ${ }^{1} \mathrm{H}$ relaxation properties $\left(\mathrm{T}_{1}\right)$ can be related to the relative proximity of the 217 surface protonated species to the sorbed paramagnetic species, and can be used to further 218 constrain the structural models for the sorption process (Table 2). The results, again, indicate that 219 the paramagnets are most closely associated with sorbed surface water, but do exert some 220 influence on the $>\mathrm{SiOH}_{\mathrm{s}}$ and $>\mathrm{SiOH}_{\mathrm{w}}$ species. The observed ${ }^{1} \mathrm{H} \mathrm{T}_{1}$ can be thought to contain 221 contributions from two separate interactions through the relation:

$$
1 / \mathrm{T}_{1}=1 / \mathrm{T}_{1 \mathrm{P}}+1 / \mathrm{T}_{1 \mathrm{dia}}
$$

223 where $1 / \mathrm{T}_{1 \mathrm{P}}$ is the contribution from the paramagnetic species, and $1 / \mathrm{T}_{1 \text { dia }}$ is the contribution

224 from all other diamagnetic interactions (e.g. ${ }^{1} \mathrm{H}-{ }^{1} \mathrm{H}$ spin diffusion, and ${ }^{1} \mathrm{H}-{ }^{29} \mathrm{Si}$ dipole

225 coupling).[23] The paramagnetic contribution here is proportional to the distance (r) between ${ }^{1} \mathrm{H}$ 226 and the paramagnet center and the number of the paramagnetic species $\left(\mathrm{N}_{\mathrm{P}}\right)$.[34] 


$$
1 / \mathrm{T}_{1 \mathrm{P}} \alpha \mathrm{N}_{\mathrm{P}} \cdot 1 / \mathrm{r}^{6}
$$

228 We use the above relationships only as guides for the discussion of the measured $\mathrm{T}_{1}$ values and

229 how we can relate these to relative proximity of the paramagnet species. In general, we can state 230 that the $\mathrm{T}_{1}$ of a ${ }^{1} \mathrm{H}$ species will decrease if either the distance to the paramagnet decrease, or the 231 density of paramagnets increases. We note the most dramatic decreases of the $\mathrm{T}_{1}$ values relative 232 to the control for the residual water peaks, followed by the $>\mathrm{SiOH}_{\mathrm{s}}$ sites (Table 2). With the 233 exception of the highest surface loading $\mathrm{Cu}$ sample, the $\mathrm{T}_{1}$ of the $>\mathrm{SiOH}_{\mathrm{w}}$ is largely unaffected.

234 These data indicate that in the $\mathrm{Cu}$ system, at the highest loadings, the paramagnet is in close 235 enough proximity to affect the relaxation properties of the $>\mathrm{SiOH}_{\mathrm{w}}$. In all other samples, the 236 paramagnet species are most closely associated with surface sorbed water, and the strongly H237 bonded silanol sites.

238 Sorption complexation models

239 We frame these results within the context of simple sorption models where the metals 240 sorb to a single type of surface site. In the Ni system we propose that the sorption behavior 241 observed can be explained by a single surface reaction.

$$
>\mathrm{SiO}^{-}{ }_{(\text {external })}+\mathrm{Ni}^{2+} \leftrightarrow>\mathrm{SiONi}^{+}{ }_{(\text {external })}
$$

243 The ${ }^{1} \mathrm{H}$ data indicate that the $\mathrm{Ni}$ does not interact with the internal silanol sites $\left(>\mathrm{SiOH}{ }_{\mathrm{w}}\right)$, and

244 that all the sorption reactions occur at the external surface sites. In the $\mathrm{Cu}$ system, the data 245 suggests that a two stage sorption model is necessary to describe the ${ }^{29} \mathrm{Si}\left\{{ }^{1} \mathrm{H}\right\} \mathrm{CP} / \mathrm{MAS}$ and ${ }^{1} \mathrm{H}$ 246 NMR data. At lower concentrations the $\mathrm{Cu}$ sorbs following the reaction:

$$
>\mathrm{SiO}_{(\text {external })}^{-}+\mathrm{Cu}^{2+} \leftrightarrow>\mathrm{SiOCu}^{+}{ }_{(\text {external })}
$$

248 As these external sites become less favorable at higher surface coverages the $\mathrm{Cu}$ then sorbs at 249 sites within the internal pore spaces via: 


$$
>\mathrm{SiO}^{-}{ }_{\text {(internal) }}+\mathrm{Cu}^{2+} \leftrightarrow>\mathrm{SiOCu}^{+}{ }_{\text {(internal) }}
$$

251 This second step is evidenced by the shortening of the $>\mathrm{SiOH}_{\mathrm{w}} \mathrm{T}_{1}$ as the $\mathrm{Cu}$ loading increases

252 which indicates a closer association of the $\mathrm{Cu}$ with these internal sites. It is unclear why these

253 same processes are not active in the Ni system. One possible explanation could be that diffusion

254 of large Ni complexes to these internal sites is limited. More work is necessary to determine if

255 these processes are active. In general, these results agree well with previous solution chemistry

256 studies which predict the inner sphere sorption of $\mathrm{Cu}$ and $\mathrm{Ni}$ at the silica surface. [3, 35] We

257 believe that the NMR techniques presented here can be easily extended to probe a range of

258 interactions between paramagnetic sorbates and diamagnetic surfaces. The results of such studies

259 should help grow our understanding of the basic reactions needed to model the fate and transport 260 of metals.

261 ACKNOWLEDGEMENTS

262 This work was funded by the U.S. Department of Energy's Office of Science through Basic

263 Energy Science Geosciences Division and the Subsurface Biogeochemical Research program

264 within the Biological and Environmental Research, Climate and Environmental Sciences

265 Division. This work was also performed under the auspices of the U.S. Department of Energy by

266 Lawrence Livermore National Laboratory under Contract W-7405-Eng-48 and Contract DE-

267 AC52-07NA27344 


\section{FIGURE CAPTIONS}

270 Figure 1. ${ }^{29} \mathrm{Si}\left\{{ }^{1} \mathrm{H}\right\} \mathrm{CP} / \mathrm{MAS}$ spectra collected contact time of $2 \mathrm{~ms}$ (left) and $7 \mathrm{~ms}$ (right) for the $271 \mathrm{pH} 9$ control sample, and two Ni sorption samples.

272

273 Figure 2. Results of chemometrics analysis for the $\mathrm{pH} 9$ Control sample A. The two components 274 which fully describe the intensity variation. B. The intensity versus contact time profiles for the $275>\mathrm{SiO}^{-}$and $>\mathrm{SiOH}$ components. $\mathrm{C}$. The intensity profile of the $>\mathrm{SiO}^{-}$The dotted lines are present 276 only to guide the eye.

278 Figure 3. The results of chemometrics analysis for the $\mathbf{a}-\mathbf{b}) \mathrm{Cu}$ and $\mathbf{c}-\mathbf{d}) \mathrm{Ni}$ sorption samples 279 compared to that obtained for their respective control samples. All spectra were collected for the 280 same number of acquisitions (4096) and their intensities are scaled based on their measured 281 weights.

282

283 Figure 4. Schematic representations of ${ }^{1} \mathrm{H}$ magnetization transfer (blue arrows) through spin

284 diffusion between different surface silica sites. A. In the absence of paramagnetic cations

285 magnetization is shuttled from the $>\mathrm{SiOH}^{0}$ (blue) to the $>\mathrm{SiO}$ - groups (red). $\mathbf{B}$. The presence of a $286>\mathrm{SiOM}^{+}$(red and green) surface species blocks the magnetization transfer due to the presence of 287 unpaired electrons (represented by the green circle).

288

289 Figure 5. Sample ${ }^{1} \mathrm{H}$ NMR spectra collected for the a) $\mathrm{pH} 9$ control sample, and the highest 290 loaded b) $\mathrm{Cu}$ and c) $\mathrm{Ni}$ samples. 


\section{TABLES}

\begin{tabular}{|c|c|c|c|c|c|c|}
\hline Sample & pH & $\begin{array}{c}\mathrm{M}^{2+} \text { inital } \\
(\mu \mathrm{mol})\end{array}$ & $\begin{array}{l}\mathrm{M}_{\text {final }}^{2+} \\
(\mu \mathrm{mol})\end{array}$ & $\%_{\text {removed }}$ & $\begin{array}{c}\text { Bulk coverage } \\
\left(\mathrm{nmol} \mathrm{M}^{2+} / \mathrm{m}^{2} \mathrm{SiO}_{2}\right)\end{array}$ & $\%$ coverage \\
\hline $\mathrm{Cu} 01$ & 8 & 1.0 & 0.012 & 98.8 & 6.5 & 0.33 \\
\hline $\mathrm{Cu} 1$ & 8 & 10.0 & 0.15 & 98.5 & 64.4 & 3.23 \\
\hline $\mathrm{Ni} 01$ & 9 & 1.0 & 0.75 & 24.6 & 1.6 & 0.08 \\
\hline $\mathrm{Ni} 1$ & 9 & 10.0 & 1.73 & 82.6 & 54.0 & 2.71 \\
\hline
\end{tabular}

293 Table 1: Results of solution chemistry measured for the sorption experiments. The \% coverage is 294 calculated assuming a surface silanol density of $2 \mu \mathrm{mol} / \mathrm{m}^{2}$ (see text).

295

\begin{tabular}{|c|c|c|c|}
\hline Sample & Site & Chemical Shift (ppm) & $\mathbf{T}_{\mathbf{1}}(\mathbf{m s )}$ \\
\hline Control pH 9 & $>\mathrm{SiOH}_{\mathrm{s}}$ & 5.82 & $250 \pm 2$ \\
& $\mathrm{H}_{2} \mathrm{O}$ & 4.74 & $155 \pm 1$ \\
& $>\mathrm{SiOH}_{\mathrm{w}}$ & 2.38 & $581 \pm 15$ \\
\hline $\mathrm{Cu} 01$ & $>\mathrm{SiOH}_{\mathrm{s}}$ & 5.46 & $140 \pm 1$ \\
& $\mathrm{H}_{2} \mathrm{O}$ & 4.92 & $89.2 \pm 0.1$ \\
& $>\mathrm{SiOH}_{\mathrm{w}}$ & 2.38 & $612 \pm$ \\
\hline $\mathrm{Cu} 1$ & $>\mathrm{SiOH}_{\mathrm{s}}$ & 5.54 & $110 \pm 1$ \\
& $\mathrm{H}_{2} \mathrm{O}$ & 4.56 & $38.1 \pm 0.1$ \\
& $>\mathrm{SiOH}_{\mathrm{w}}$ & 2.37 & $317 \pm 1$ \\
\hline $\mathrm{Ni} \mathrm{01}$ & $>\mathrm{SiOH}_{\mathrm{s}}$ & 5.48 & $105 \pm 1$ \\
& $\mathrm{H}_{2} \mathrm{O}$ & - & - \\
& $>\mathrm{SiOH}_{\mathrm{w}}$ & 2.38 & $685 \pm 1$ \\
\hline $\mathrm{Ni} 1$ & $>\mathrm{SiOH}_{\mathrm{s}}$ & 5.48 & $106 \pm 1$ \\
& $\mathrm{H}_{2} \mathrm{O}$ & - & - \\
& $>\mathrm{SiOH}_{\mathrm{w}}$ & 2.38 & $564 \pm 1$ \\
\hline
\end{tabular}

Table 2: ${ }^{1} \mathrm{H}$ MAS NMR results for the sorption samples. 


1
2
3
4
5
6
7
8
9
10
11
12
13
14
15
16
17
18
19
20
21
22
23
24
25
26
27
28
29
30
31
32
33
34
35
36
37
38
39
40
41
42
43
44
45
46
47
48
49
50
51
52
53
55
50

297

298

7 (

10

11

13

14

15

16

17

18

19

20

21

23

24

25

26

27
28

29

30

31

35

36

37

38

39

40

41

42

44

45

46

47

48

49

50

51

52

56

57

58

59

60 
$300 \quad$ 1. Davis, J. A.; James, R. O.; Leckie, J. O., Surface ionization and complexation at the 301 oxide/water interface: I. Computation of electrical double layer properties in simple electrolytes. 302 Journal of Colloid and Interface Science 1978, 63, (3), 480-499.

303 2. Dzombak, D. A.; Morel, F. o. M. M., Surface complexation modeling : hydrous ferric 304 oxide. Wiley: New York, 1990; p xvii, 393 p.

305 3. Criscenti, L. J.; Sverjensky, D. A., The role of electrolyte anions $(C l O(4)(-), N O(3)(-)$, 306 and $\mathrm{Cl}(-))$ in divalent metal $(M(2+))$ adsorption on oxide and hydroxide surfaces in salt 307 solutions. American Journal of Science 1999, 299, (10), 828-899.

308 4. Sverjensky, D. A., Interpretation and prediction of triple-layer model capacitances and 309 the structure of the oxide-electrolyte-water interface. Geochimica et Cosmochimica Acta 2001, 310 65, (21), 3643-3655.

311 5. Criscenti, L. J.; Sverjensky, D. A., A single-site model for divalent transition and heavy 312 metal adsorption over a range of metal concentrations. Journal of Colloid and Interface Science 313 2002, 253, (2), 329-352.

$314 \quad$ 6. $\quad$ Karamalidis, A. K.; Dzombak, D. A., Surface complexation modeling : gibbsite. Wiley: 315 Hoboken, N.J., 2010; $p x v, 294$ p.

316 7. Xia, K.; Mehadi, A.; Taylor, R. W.; Bleam, W. F., X-ray absorption and electron 317 paramagnetic resonance studies of $C u(I I)$ sorbed to silica: Surface-induced precipitation at low 318 surface coverages. Journal of Colloid and Interface Science 1997, 185, (1), 252-257.

$319 \quad$ 8. Xia, K.; Taylor, R. W.; Bleam, W. F.; Helmke, P. A., The distribution of Cu(II) on 320 boehmite and silica surfaces: Correlating EPR signal loss with the effective Bohr magneton 321 number of sorbed ions. Journal of Colloid and Interface Science 1998, 199, (1), 77-82.

322 9. Cheah, S. F.; Brown, G. E.; Parks, G. A., XAFS spectroscopy study of Cu(II) sorption on 323 amorphous $\mathrm{SiO} 2$ and gamma-Al2O3: Effect of substrate and time on sorption complexes.

324 Journal of Colloid and Interface Science 1998, 208, (1), 110-128.

325 10. Cheah, S. F.; Brown, G. E.; Parks, G. A., XAFS study of Cu model compounds and Cu2+ 326 sorption products on amorphous SiO2, gamma-Al2O3, and anatase. American Mineralogist 327 2000, 85, (1), 118-132.

328 11. Motschi, H., Correlation of EPR-parameters with thermodynamic stability constants for 329 copper(II) complexes Cu(II)-EPR as a probe for the surface complexation at the water/oxide 330 interface. Colloids and Surfaces 1984, 9, (4), 333-347.

331 12. Hyun, S. P.; Cho, Y. H.; Hahn, P. S., An electron paramagnetic resonance study of Cu(II) 332 sorbed on quartz. Journal of Colloid and Interface Science 2003, 257, (2), 179-187.

333 13. Roberts, D. R.; Scheidegger, A. M.; Sparks, D. L., Kinetics of Mixed Ni-Al Precipitate

334 Formation on a Soil Clay Fraction. Environmental Science \& Technology 1999, 33, (21), 37493353754.

336 14. Scheinost, A. C.; Ford, R. G.; Sparks, D. L., The role of Al in the formation of secondary 337 Ni precipitates on pyrophyllite, gibbsite, talc, and amorphous silica: a DRS study. Geochimica et 338 Cosmochimica Acta 1999, 63, (19-20), 3193-3203.

339 15. Scheinost, A. C.; Sparks, D. L., Formation of Layered Single- and Double-Metal 340 Hydroxide Precipitates at the Mineral/Water Interface: A Multiple-Scattering XAFS Analysis. 341 Journal of Colloid and Interface Science 2000, 223, (2), 167-178. 
342 16. Sheng, G.; Yang, S.; Sheng, J.; Hu, J.; Tan, X.; Wang, X., Macroscopic and Microscopic 343 Investigation of Ni(II) Sequestration on Diatomite by Batch, XPS, and EXAFS Techniques.

344 Environmental Science \& Technology 2011, 45, (18), 7718-7726.

345 17. Carroll, S. A.; Maxwell, R. S.; Bourcier, W.; Martin, S.; Hulsey, S., Evaluation of silica346 water surface chemistry using NMR spectroscopy. Geochimica Et Cosmochimica Acta 2002, 66, 347 (6), 913-926.

$348 \quad$ 18. Houston, J. R.; Herberg, J. L.; Maxwell, R. S.; Carroll, S. A., Association of dissolved 349 aluminum with silica: Connecting molecular structure to surface reactivity using NMR.

350 Geochimica Et Cosmochimica Acta 2008, 72, (14), 3326-3337.

351 19. Kim, Y.; Kirkpatrick, R. J., Na-23 and Cs-133 NMR study of cation adsorption on 352 mineral surfaces: Local environments, dynamics, and effects of mixed cations. Geochimica Et 353 Cosmochimica Acta 1997, 61, (24), 5199-5208.

354 20. Li, W.; Feng, J.; Kwon, K. D.; Kubicki, J. D.; Phillips, B. L., Surface Speciation of 355 Phosphate on Boehmite (gamma-AlOOH) Determined from NMR Spectroscopy. Langmuir 2010, 356 26, (7), 4753-4761.

357 21. Mason, H. E.; Maxwell, R. S.; Carroll, S. A., The formation of metastable 358 aluminosilicates in the Al-Si-H2O system: Results from solution chemistry and solid-state NMR 359 spectroscopy. Geochimica et Cosmochimica Acta 2011, 75, (20), 6080-6093.

360 22. Wickramasinghe, N. P.; Ishii, Y., Sensitivity enhancement, assignment, and distance 361 measurement in 13C solid-state NMR spectroscopy for paramagnetic systems under fast magic 362 angle spinning. Journal of Magnetic Resonance 2006, 181, (2), 233-243.

363 23. Wickramasinghe, N. P.; Shaibat, M. A.; Ishii, Y., Elucidating connectivity and metal364 binding structures of unlabeled paramagnetic complexes by $\mathrm{C}$-13 and $\mathrm{H}$-1 solid-state NMR 365 under fast magic angle spinning. Journal of Physical Chemistry B 2007, 111, (33), 9693-9696.

366 24. Cordella, C., Principal component analysis: the basic building block of chemometrics. 367 Actual Chimique 2010, (345), 13-18.

368 25. Ayoko, G. A.; Mostert, M. M. R.; Kokot, S., Application of chemometrics to analysis of 369 soil pollutants. Trac-Trend Anal Chem 2010, 29, (5), 430-445.

370 26. Hasegawa, T., Chemometrics for spectroscopic analysis. Anal Bioanal Chem 2003, 375, 371 (1), 18-19.

372 27. Maeder, M., Evolving factor analysis for the resolution of overlapping chromatographic 373 peaks. Analytical Chemistry 1987, 59, (3), 527-530.

374 28. de Juan, A.; Tauler, R., Chemometrics applied to unravel multicomponent processes and 375 mixtures - Revisiting latest trends in multivariate resolution. Anal Chim Acta 2003, 500, (1-2), $376 \quad 195-210$.

377 29. Tauler, R., Multivariate curve resolution applied to second order data. Chemometr Intell 378 Lab 1995, 30, (1), 133-146.

379 30. Liu, C. H. C.; Maciel, G. E., The fumed silica surface: A study by NMR. Journal of the 380 American Chemical Society 1996, 118, (21), 5103-5119.

381 31. Kolodziejski, W.; Klinowski, J., Kinetics of cross-polarization in solid-state NMR: A 382 guide for chemists. Chemical Reviews 2002, 102, (3), 613-628.

383 32. Crank, J., The mathematics of diffusion. Clarendon Press: Oxford,, 1956; $p 347$.

384 33. Loucaides, S.; Behrends, T.; Van Cappellen, P., Reactivity of biogenic silica: Surface

385 versus bulk charge density. Geochimica Et Cosmochimica Acta 2010, 74, (2), 517-530. 
1

2

3

4

5

6

7

8

9

10

11

12

13

14

15

16

17

18

19

20

21

22

23

24

25

26

27

28

29

30

31

32

33

34

35

36

37

38

39

40

41

42

43

44

45

46

47

48

49

50

51

52

53

54

55

56

57

58

59

60
386 34. Voronov, V. K.; Keiko, V. V.; Moskovskaya, T. E., Paramagnetic reagents for the study of 387 the structure of heteroatomic compounds from the NMR spectra. Journal of Structural Chemistry 388 1977, 18, (5).

389 35. Vlasova, N. N., Adsorption of Cu2+ ions onto silica surface from aqueous solutions 390 containing organic substances. Colloids and Surfaces A: Physicochemical and Engineering 391 Aspects 2000, 163, (2-3), 125-133. 

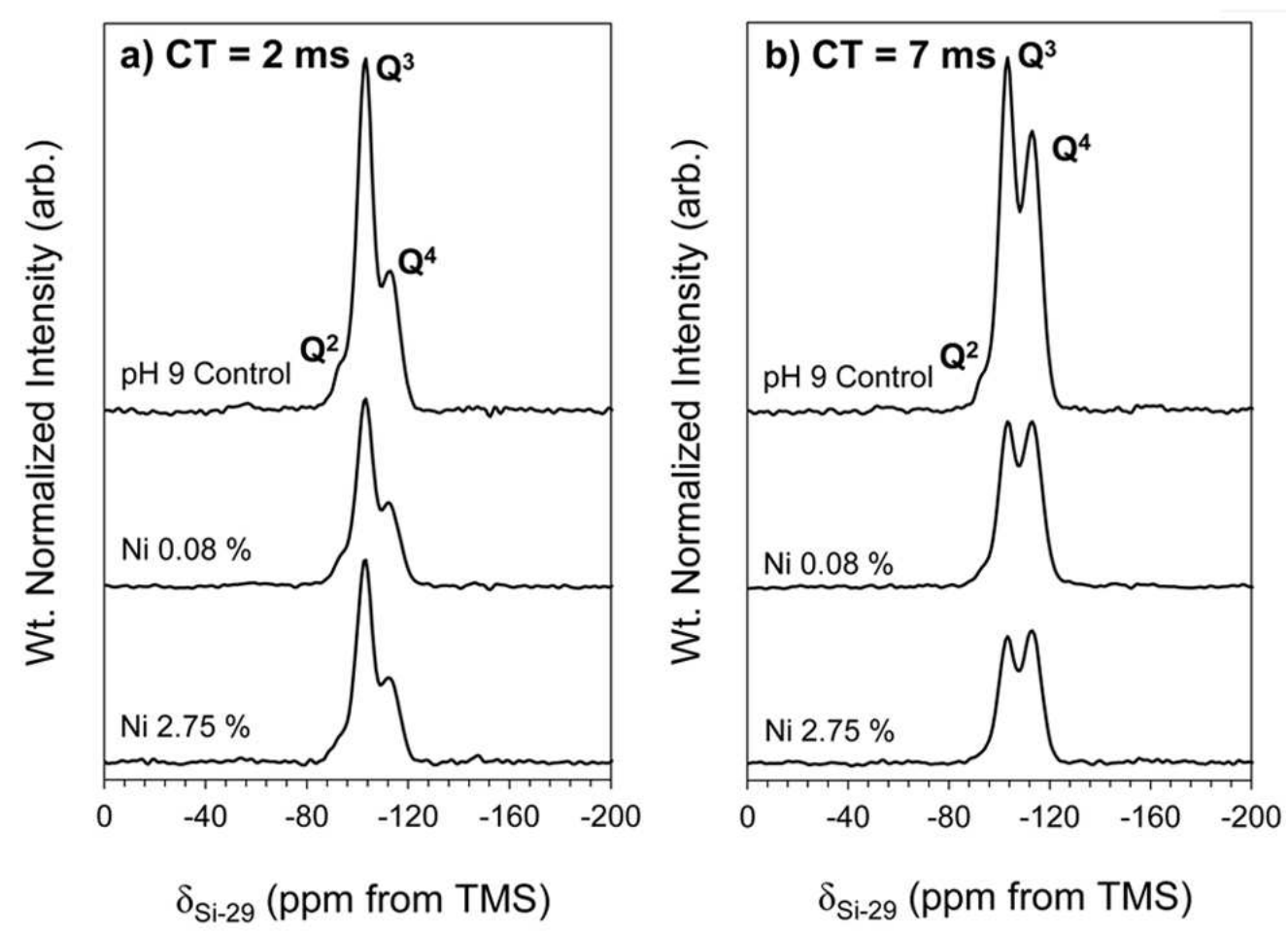

$82 \times 60 \mathrm{~mm}(300 \times 300$ DPI $)$ 

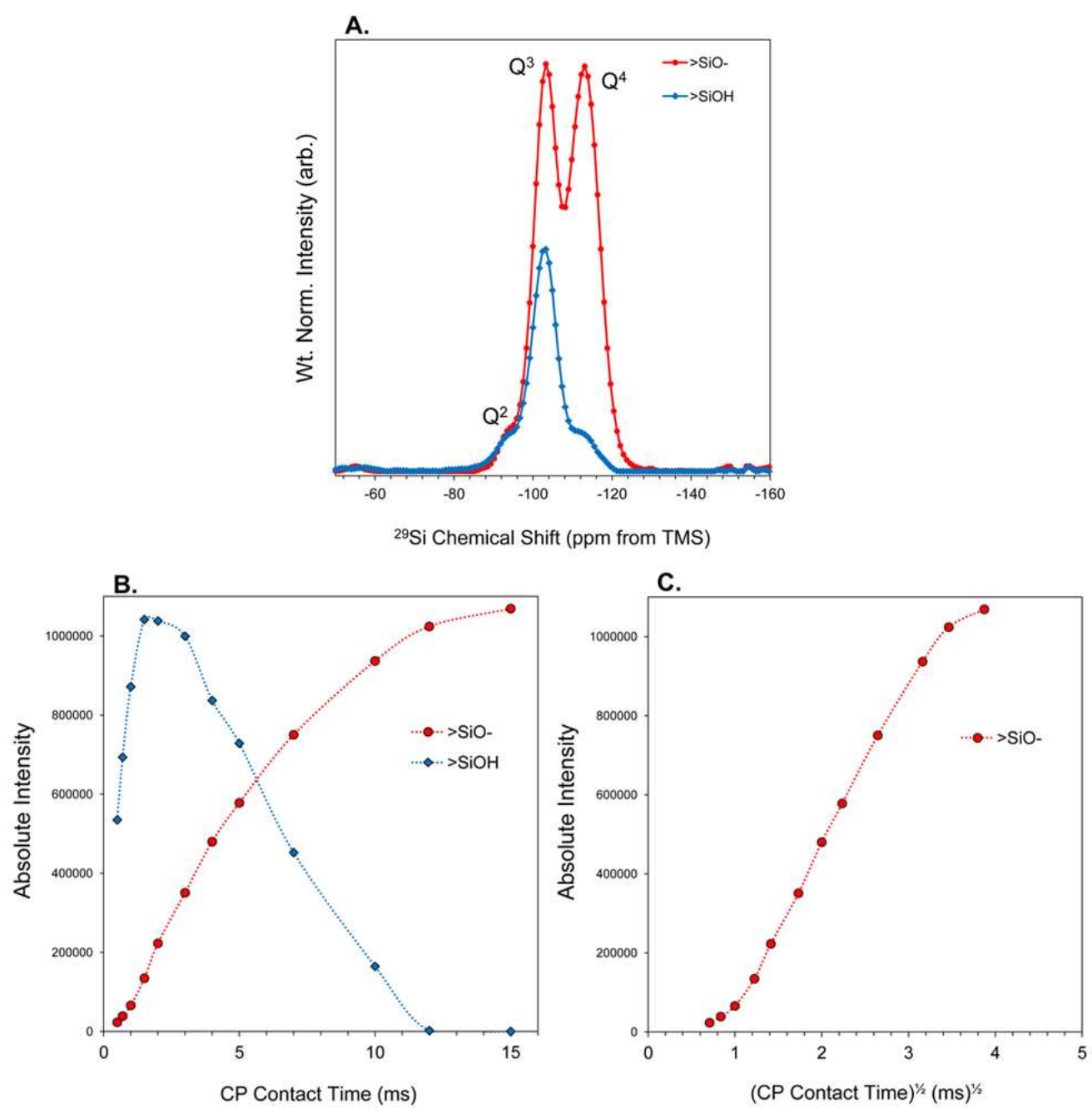

$82 \times 84 \mathrm{~mm}(300 \times 300$ DPI $)$ 

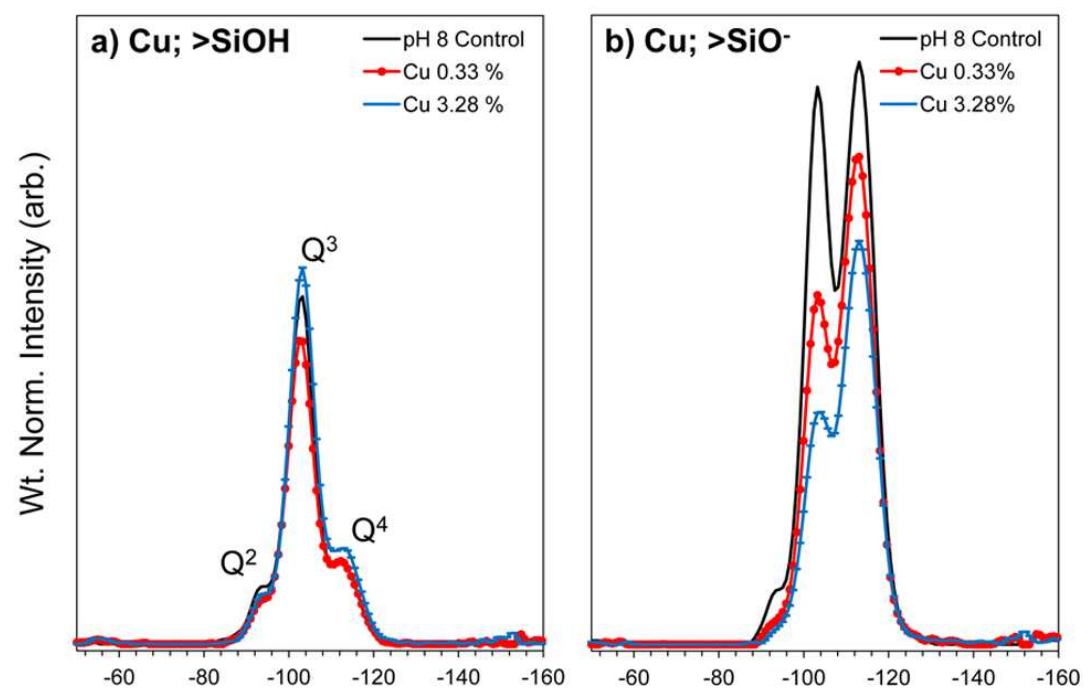

${ }^{29}$ Si Chemical Shift (ppm from TMS)

${ }^{29}$ Si Chemical Shift (ppm from TMS)
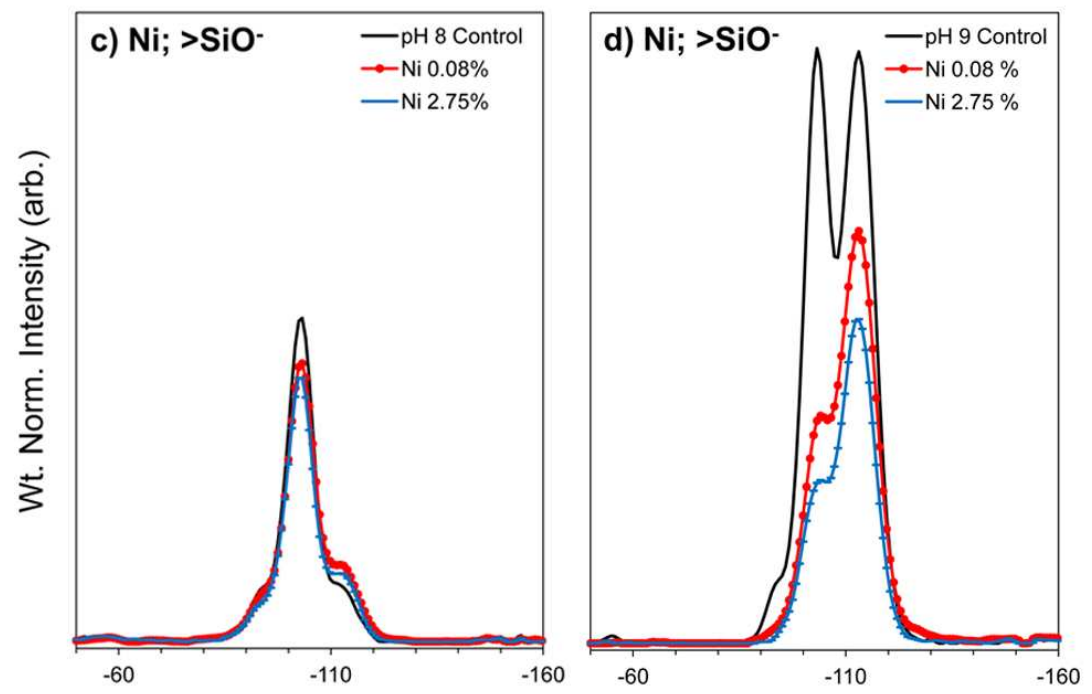

${ }^{29} \mathrm{Si}$ Chemical Shift (ppm from TMS)

${ }^{29} \mathrm{Si}$ Chemical Shift (ppm from TMS)

$82 \times 119 \mathrm{~mm}(300 \times 300$ DPI $)$ 


1
2
3
4
5
6
7
8
9
10
11
12
13
14
15
16
17
18
19
20
21
22
23
24
25
26
27
28
29
30
31
32
33
34
35
36
37
38
39
40
41
42
53
50
50
49
50
50
51
53
54

A.

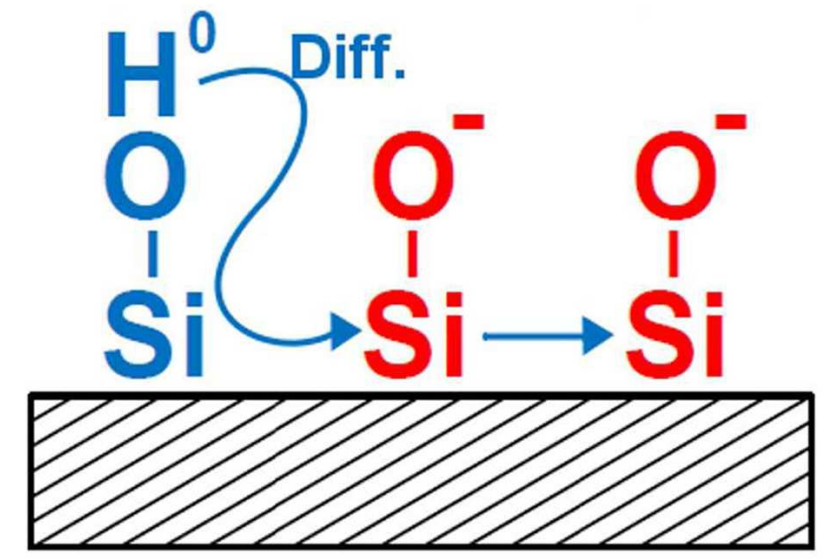

D.

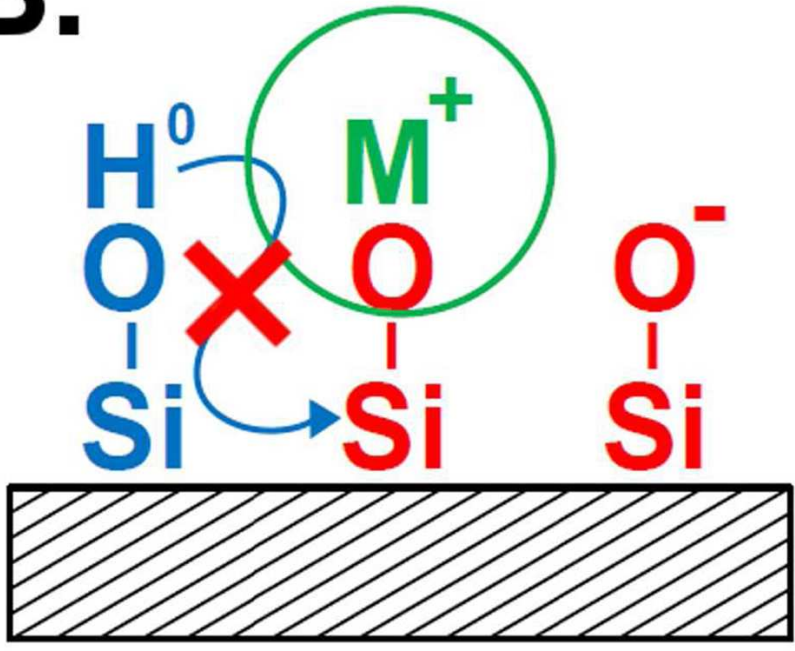

$82 \times 152 \mathrm{~mm}(300 \times 300 \mathrm{DPI})$ 


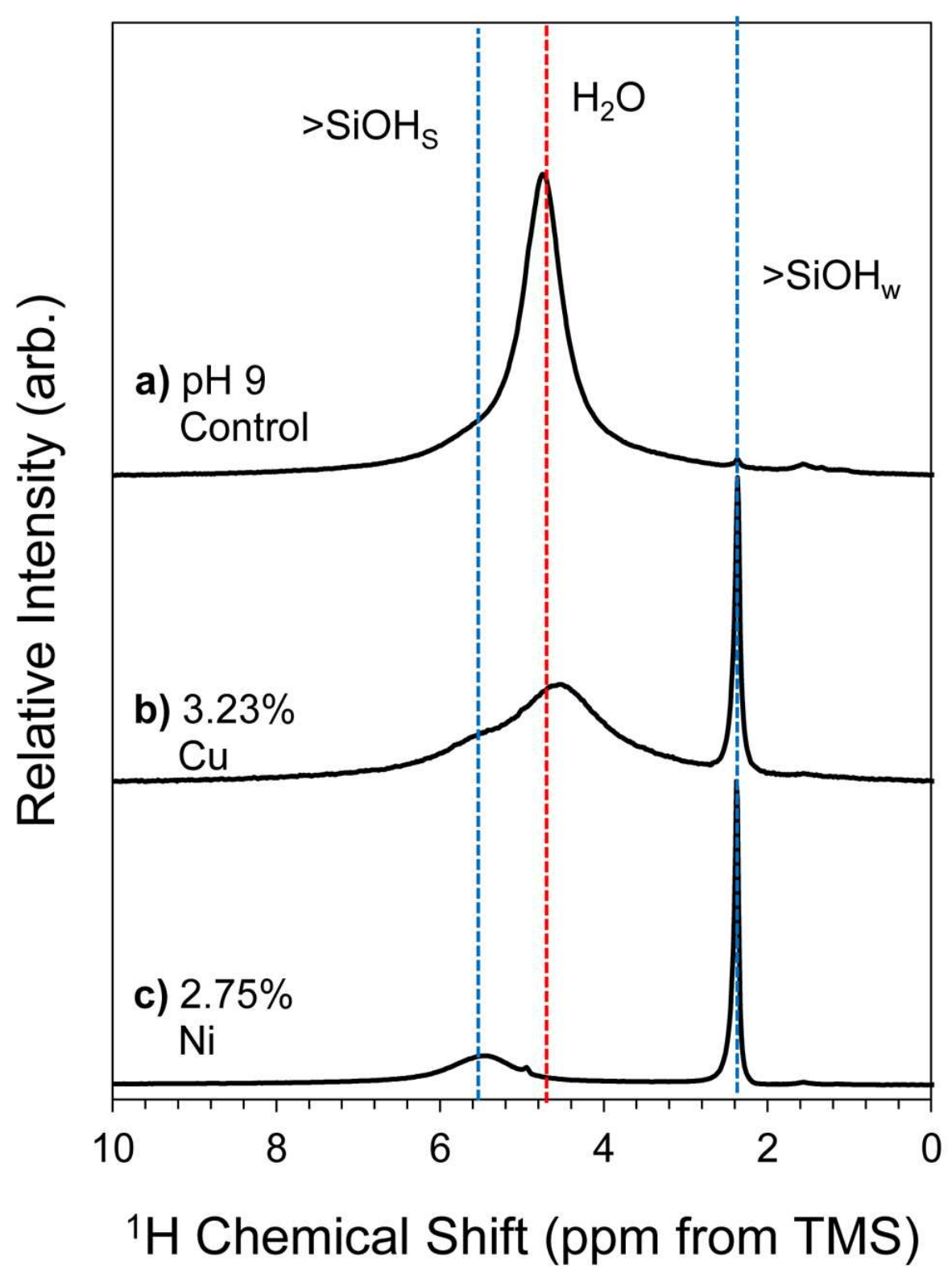

$82 \times 110 \mathrm{~mm}(300 \times 300$ DPI $)$ 


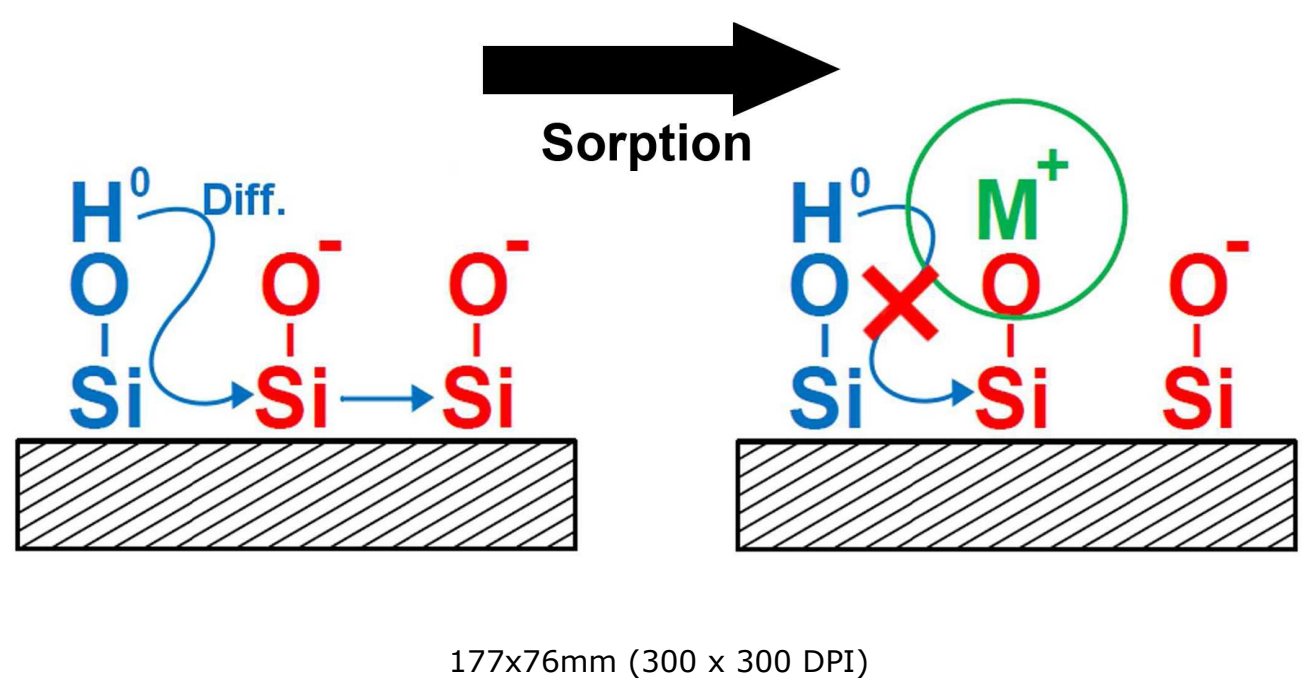

